Design Input Request
CRWMS/M\&O

1261 TOWN CENTER DRIVE, LAS VEGAS, NV 89134

6. DESCRIPTION, TITLE, SUBJECT

LADS PHASE I CONFIDENCE ASSESSMENTS

\begin{tabular}{|l|l}
\hline 7. NEED DATE OF DESIGN INPUT & 8. DESIGN INPUT NEEDED FOR WORK SUBJECT TO QARD REQUIREMENTS
\end{tabular}

\begin{tabular}{l|ll}
$03 / 12 / 99$ & $\square$ Yes $\square$ No
\end{tabular}

9. SCOPE OF DESIGN INPUT REQUESTED (Name of document(s), if known):

THE PURPOSE OF THIS QAP-3-12 REVISION IS TO ADD A REQUIREMENT THAT CONFIDENCE ASSESSMENTS BE INCLUDED IN ALL PHASE I DA/DF QAP-3-5 TECHNICAL REPORTS. A COMPLETE COPY OF THE SUMMARY OF CONFIDENCE ASSESSMENTS IS ATTACHED (TWENTY-SIX PAGES). THE APPROPRIATE INFORMATION CAN BE EXTRACTED AND THEN INCLUDED IN THE EVALUATION CRITERIA APPENDIX TO EACH DA/DF QAP-3-5 TECHNICAL DOCUMENT.

10. DESCRIPTION OF INTENDED USE OF DESIGN INPUT:

NO CHANGE

To:

11a. RESPONSIBLE MANAGER NAME

SEE ATTACHED

11d. ADDRESS

11b. ORGANIZATION

11c. TELEPHONE SEE ATTACHED 
Distribution:

M. A. Balady

G. K. Beall

S. M. Bennett

* H. A. Benton

K. K. Bhattacharyya

J. A. Blink

K. L. Coppersmith

T. A. Cotton

S. R. Dana

T. W. Doering

H. A. Dokuzoguz

R. M. Dulin

R. G. Eble

J. W. Fay

M. J. Gomez

G. W. Griffith

E. L. Hardin

C. R. Hastings

* R. L. Howard

B. E. Kirstein

D. G. McKenzie

D. A. Nitti

M. S. Rees

D. C. Richardson

S. F. Saterlie

R. S. Saunders

M. B. Skorska

O. D. Smith

E. P. Smith

G. M. Teraoka

D. W. Thomas

M. Woods

F. N. Zinkevich 
December 22, 1998

\section{CONFIDENCE ASSESSMENTS}

[Notes to Design Leads are given in italics]

\section{SCALES OF CONFIDENCE}

- High level of confidence (A): the assessment is readily supported, defensible, and not subject to much uncertainty

- Moderately high (B): the assessment is supportable, reasonably defensible, and only subject to moderate uncertainty

- Moderate (C): the assessment is supportable, reasonably defensible with some possible weaknesses, and subject to moderate levels of uncertainty

- Moderately low (D): the assessment is not well supported, has some weaknesses in terms of defensibility, and subject to uncertainty

- Low $(E)$ : the assessment is not well supported, has significant weaknesses in terms of defensibility, and subject to considerable uncertainty

Note that for each Design Feature (DF) and Design Alternative (DA), two assessments are made for postclosure performance: one by the lead design engineer (LDE) and another by the performance assessment analyst (PA analyst).

\section{DESIGN FEATURES}

\section{DF 1 - CERAMIC COATINGS}

\section{Postclosure Performance (LDE)--}

Moderately low (D) level of confidence. The corrosion model abstraction is conservative, and shows the ceramic coating spalling off the waste package when the metal substrate fails.

\section{Postclosure Performance (PA Analyst)-}

Low (E) level of confidence. Virtually no plausible degradation mode data are available and corrosion model presently not supportable.

Preclosure Performance-

Moderately high (B) level of confidence. This feature would require more handling of waste packages, so there could be a slight increase in DBEs.

Assurance of Safety-

Moderately high (B) level of confidence. Additional studies are needed to provide confidence that the coating will remain on the waste packages.

$$
\angle A D-X X-99018 \cdot R a
$$


QAP 3-12

Request for Design Input

$2 / 1 / 99$

\section{Engineering Acceptance-}

Moderately low (D) level of confidence. There are no licensing precedents for ceramic coatings and their safety may be difficult to defend.

Construction, Operations and Maintenance--

Moderately high (B) level of confidence. No problems with industrial safety are anticipated. Ceramic coatings have been used in radioactive applications at Los Alamos National Laboratory.

\section{Schedule-}

Moderate (C) level of confidence. The licensing stage could require more time due to the longer time required for testing.

Cost -

Moderately low (D) level of confidence. More information needed; confidence will probably increase within the next few months (currently have limited information from only one vendor.)

\section{DF 2 -DRIP SHIELDS}

\section{Postclosure Performance (LDE) -}

Moderately low (D) level of confidence. PA models incorporate some soil physics aspects that are well understood (e.g., water flow through a pipe) but there is uncertainty regarding the chain of events that could result in water entering the drifts and hitting a drip shield. The amount of water entering the drifts is uncertain (a range of $1 \mathrm{~mm}$ to 300 $\mathrm{mm}$ ) as are issues such as where does the water enter and how is it dispersed?

Additionally, the PA models do not consider the damage that could be caused to the drip shield during emplacement or possible local humid environments that might occur under the drip shield.

\section{Postclosure Performance (PA Analyst) -}

Moderately high (B) level of confidence. The amount of water assumed to hit the drip shield is half of what has been modeled for the waste packages (one-half of the surface area). The model assumes no localized attack and no wicking of seepage.

\section{Preclosure Performance-}

NA ???

Assurance of Safety-

Moderate (C) level of confidence. Although higher confidence is indicated by data suggesting a 10,000 year life for the corrosion-resistant material to be used (Alloy 22), other mechanisms that are not clearly understood. For example, humidity could affect the long-term performance of the drip shield. True long-term performance cannot be known, and since at the time of repository closure the shield will be covered with backfill, demonstrating performance will be difficult. 


\section{Engineering Acceptance-}

High (A) level of confidence. Drip shields are very easy to demonstrate and additional materials testing planned should provide high confidence in the shield performance.

\section{Construction, Operation and Maintenance-}

High (A) level of confidence. The system can be designed readily to accommodate any identified challenges.

\section{Schedule -}

High (A) level of confidence. Straightforward design issue, and ample time to construct this feature.

Cost-

Moderately high (B) level of confidence. There is good control on the cost of materials that will be needed (but some uncertainty regarding installation-true??)

\section{DF 3-BACKFILL}

\section{Postclosure Performance (LDE) -}

Moderately low $(\mathrm{D}+)$ level of confidence. The specific properties of the backfill material to be used are not incorporated (e.g., particle shape, mineralogy, and size distribution) and the influence of water and geochemistry is not clearly understood.

\section{Postclosure Performance (PA Analyst) -}

Moderately high (B) level of confidence. The UZ flow properties and their effect on the relative humidity in drifts are uncertain, however the range in these properties is likely to be small. The possibility that seepage would be focused onto the waste packages needs to be studied in more detail. Changes in the amount of seepage and the potential for rock fall are not accounted for in the model.

\section{Preclosure Performance-}

NA

\section{Assurance of Safety-}

Moderate (C) level of confidence. The potential effectiveness is not clearly understood. Additional tests could provide useful design information.

\section{Engineering Acceptance-}

Moderately high (B) level of confidence. The design and function are relatively simple, and there are numerous precedents in mining applications (e.g., filling voids)

\section{Construction, Operation, and Maintenance-}

Moderately high (B) level of confidence. The construction aspects are well understood, and once in place no maintenance is required. The confidence is not high because 
QAP 3-12

Request for Design Input

2/1/99

interactions of all elements are not well understood, and implementation is far in the future.

\section{Schedule-}

Moderately high (B) level of confidence. Backfill will be installed at closure, and should not have any unanticipated effects.

Cost-

Moderately high (B) level of confidence.

\section{DF 4 -AGING AND BLENDING OF WASTE}

Postclosure Performance (LDE) -

High (A) level of confidence. Models used for PA are conservative and defendable.

\section{Postclosure Performance (PA Analyst) -}

Moderate to moderately high $(\mathrm{C}+)$ level of confidence. There is higher confidence in the temperatures obtained from heat output modeling and lower confidence in the relative humidity assessments. The RH values are more uncertain because of possible irreversible changes in rock properties following the thermal period. Because a isothermal flux model is used, the local distribution of the percolation flux is not well represented.

\section{Preclosure Performance-}

Moderately high (B) level of confidence for blending and moderate $(C)$ level of confidence for aging. Blending expands the pool in the waste handling building. This feature will require equipment that could increase the potential for a DBE. (specific basis for aging?)

\section{Assurance of Safety-}

High (A) level of confidence. These features are similar to the VA base case design.

\section{Engineering Acceptance-}

Moderately high (B) level of confidence. Postclosure performance may be difficult to demonstrate; there are no licensing precedents.

\section{Construction, Operations and Maintenance-}

Moderate (C) level of confidence for blending (info. needed for aging.) The level of confidence will increase with additional information.

\section{Schedule-}

Moderately low (D) level of confidence. There are no licensing precedents, so these features could take longer to defend during licensing. The aging option could be perceived to be an interim storage option that would have regulatory implications. 
QAP 3-12

Request for Design Input

$2 / 1 / 99$

Cost-

NR (no cost information available yet)

\section{DF 7 - CONTINUOUS PRECLOSURE VENTILATION}

\section{Postclosure Performance (LDE) -}

Moderately low (D) level of confidence. The PA model is not realistic. Data from a single borehole were used to build the model and a limitless reservoir of water is assumed. The influence of moisture is not included in the thermal modeling.

\section{Postclosure Performance (PA Analyst) -}

Moderate (C) level of confidence. Uncertainty in rock property effects, particularly rock re-wetting time after the thermal period is over.

\section{Preclosure Performance-}

High (A) level of confidence. This feature is similar to the VA base case design. There may some decrease in the rockfall prbability.

\section{Assurance of Safety-}

Moderately high (B) level of confidence. This feature is similar to the VA base case design.

\section{Engineering Acceptance-}

High (A) level of confidence. This is just the VA reference design with more openings; easy to demonstrate and defend.

\section{Construction, Operations and Maintenance-}

Moderately high (B) level of confidence. No special equipment will be required. There will be more openings to construct and inspect. There are more fans, but they lie within the range of existing systems.

\section{Schedule-}

Moderately high (B) level of confidence. Assuming that two TBMs are used there would be no impact on the existing schedule. The advance rates are aggressive, but possible.

\section{Cost-}

High (A) level of confidence. Key cost components are electrical power and large vertical shafts, which would be drill and blast. This is not difficult to estimate within the $\pm 50 \%$ for conceptual design. 


\section{QAP 3-12}

Request for Design Input

DF 8 - ROD CONSOLIDATION

\section{$2 / 1 / 99$}

Postclosure Performance (LDE) -

Moderate (C) level of confidence. Essentially the same model as the VA reference design is used, with a different number of waste packages and twice the number of juvenile failures.

Postclosure Performance (PA Analyst) -

Moderately high (B) level of confidence. The modeling uncertainty is reduced because the fuel cladding is assumed to be useless.

Preclosure Performance-

Moderately high (B) level of confidence. This is a fairly straightforward consideration.

Assurance of Safety-

Moderately high (B) level of confidence. It is not difficult to identify the uncertainties associated with post-closure performance for this feature.

\section{Engineering Acceptance-}

Moderately high (B) level of confidence. The activities associated with this feature, such as fuel handling, are relatively straightforward to demonstrate.

Construction, Operations and Maintenance-

Moderately high (B) level of confidence. This feature involves a mechanical operation that is not too complex.

\section{Schedule-}

Moderately low (D) level of confidence. Much work needs to be done to be able to meet the schedule for licensing. The mechanical equipment need to be designed and tested. There may be different design and tools for different assembly types.

\section{Cost-}

Moderate (C) level of confidence. The cost estimate is not done yet, but looking at consolidation at Yucca Mountain or at utility sites. Confidence is 3 at Yucca Mountain; 1 if conducted at utilities, because of programmatic issues that need to be worked out.

\section{DF 9 -TIMING OF REPOSITORY CLOSURE}

An extension of the monitoring period is analyzed. There are 2 variations: the $1^{\text {st }}$ maintains facility for a longer monitoring period (full access for Performance Confirmation for $300 \mathrm{yrs}$ ); in the $2^{\text {nd }}$ option Performance Confirmation activities are suspended after 100 yrs. The maintenance of underground features and ground support during a 300 yr period are considered in DF 10.

\section{Postclosure and Preclosure Performance - NA}




\section{QAP 3-12 \\ Request for Design Input \\ $2 / 1 / 99$}

\section{Assurance of Safety-}

Moderately low (D) level of confidence. There is uncertainty in the frequency of the rock fall DBE. The frequency is expected to be low, but lack of data makes this position difficult to defend.

\section{Engineering Acceptance-}

Moderate (C) level of confidence. This design feature is based on the assumption of replacing equipment as needed in a 200 -year period (e.g., the rail system, doors, and other equipment). There are uncertainties in this long time-frame.

\section{Construction, Operations and Maintenance-}

Moderate $(\mathrm{C})$ level of confidence. The longer time period for operations and maintenance increases the probability of a problem developing.

\section{Schedule-}

Moderate (C) level of confidence. Schedule should not be affected unless another design feature (such as Preclosure ventilation) is associated with this feature, and there is a significant increase in the number of questions during the license application stage.

\section{Cost-}

Moderate $(\mathrm{C})$ level of confidence. This feature has a very high cost thus more uncertainty is captured within the $\pm 50 \%$ confidence interval. Replacement cycles for equipment are uncertain.

\section{DF 10 - MAINTENANCE OF UNDERGROUND FEATURES AND GROUND SUPPORT}

Postclosure Performance (LDE) -

NA

\section{Postclosure Performance (PA Analyst) -}

NA

\section{Preclosure Performance-}

Moderate $(\mathrm{C})$ level of confidence. Analyses are looking at the effectiveness of ground support under different loading conditions. The analyses are usually overly conservative.

\section{Assurance of Safety-}

NA (no postclosure implications)

\section{Engineering Acceptance-}

Moderately high (B) level of confidence. These are straightforward evaluations.

\section{Construction, Operations and Maintenance-}

Moderately high (B+) level of confidence. We have a lot of information and experience with this type of operation. The thermal load will not change things much. 
QAP 3-12

Request for Design Input

$2 / 1 / 99$

Schedule-

High (A) level of confidence. There should not be a schedule implication.

Cost-

High (A) level of confidence. There is plenty of information related to PC, subsurface, and surface cost implications.

\section{DF 11 - DRIFT DIAMETER}

Postclosure Performance (LDE) -

No PA calculations were conducted for this phase, but it was assumed that the seepage is comparable to the VA reference design.

\section{Postclosure Performance (PA Analyst) -}

Moderate $(\mathrm{C})$ level of confidence for large drift diameters (up to $8 \mathrm{~m}$ ) decreasing to a moderately low (D) level of confidence for small drift sizes $(1 \mathrm{~m})$. PA analysts do not have a good measure of performance to compare drift diameters. Seepage amount, however, is related to drift diameter. The probability of an error in assessing seepage amounts decreases with an increase in drift diameter. This is because the host rock is assumed to be a heterogeneous medium, and this continuum assumption is more accurate for larger diameter openings.

\section{Preclosure Performance-}

Moderately high (B) level of confidence. Full-diameter numerical modeling could be used in analyses; these would be more accurate than the close-form solution currently used. Specific drift diameter is important because a larger drift diameter will result in a larger rock fall drop height.

\section{Assurance of Safety-}

Moderately high (B) level of confidence. There is some uncertainty associated with DBEs and the specific drift diameter selected.

\section{Engineering Acceptance-}

Moderately high (B) level of confidence. There is uncertainty in the amount of seepage that will enter the drifts and the relationship between seepage and drift diameter. There are historical precedents for TBMs operating at all drift sizes being considered.

\section{Construction, Operation, and Maintenance-}

High (A) level of confidence. No non-standard practices anticipated. A small diameter drift could affect Performance Confirmation work. 
Schedule and Cost-

QAP 3-12

Request for Design Input

$2 / 1 / 99$

Moderate (C) level of confidence. Advance rates of TBM difficult to determine until TBM capabilities known and drift diameter specified. There is less confidence in smaller diameter drifts due to possible slow muck removal operations.

\section{DF 12 --WP SPACING AND DRIFT SPACING}

\section{Postclosure Performance (LDE) -}

Low (E) level of confidence. The closer spacing between waste packages considered for this feature would result in thermal line loading above the drift. Theoretically, an umbrella effect would occur in which moisture moving toward the area above the drift would be diverted by the high thermal load into the pillar areas between the drifts, thus avoiding the waste packages. However, PA models do not indicate a difference between this and other layouts. Low confidence is based on a lack of understanding of how modeled by PA.

\section{Postclosure Performance (PA Analyst) -}

Moderately high (B) level of confidence with backfill and moderate (C) without backfill. This feature could impact seepage. There would probably be a decrease in seepage amount, but this issue needs to be studied in more detail to assess potential effect.

Preclosure Performance-

Moderate $(C)$ level of confidence. No effect anticipated.

\section{Assurance of Safety-}

Moderate $(\mathrm{C})$ level of confidence. If this feature were selected on the basis of the umbrella theory, this concept would have to be defended during licensing. This could be a difficult challenge.

\section{Engineering Acceptance-}

Moderately high (B) level of confidence. Not difficult to implement and there should be high acceptance.

\section{Construction, Operations and Maintenance-}

Moderately high (B) level of confidence. There are no major differences from the VA reference design. Performance confirmation activities could be affected, since the PC drifts lie above the emplacement drifts.

\section{Schedule-}

Moderately high (B) level of confidence. Emplacement could take longer since waste packages will be close together, but fewer drifts will be excavated.

\section{Cost-}

Moderately high (B) level of confidence. More manpower will be required but less excavation work. 
QAP 3-12

Request for Design Input

$2 / 1 / 99$

\section{DF 13 - WP SELF SHIELDING}

Postclosure Performance (LDE) -

Two implementations of this feature are a magnetite concrete shield and a ducrete shield. The ducrete was not considered by PA.

Moderately low (D) level of confidence. Only the chemistry associated with concretemodified water is considered, the same as the chemistry associated with the concrete drift lining. This may be nonconservative because the concrete shield would be in contact with the waste package. The degradation of the concrete is not modeled. It is expected that ducrete would not survive the thermal environment $\left(>250^{\circ} \mathrm{C}\right)$.

Postclosure Performance (PA Analyst) -

NA (because only considered using present assumptions about concrete-modified water)

Preclosure Performance-

Moderately high $(\mathrm{C}+$ ) level of confidence. Based on number and weight of waste packages, assuming no additional lifting.

\section{Assurance of Safety-}

Moderately low (D+) level of confidence. Significant uncertainties exist regarding the assumptions about chemistry of water, the temperatures on the waste package surface, etc.

\section{Engineering Acceptance-}

Moderate $(\mathrm{C}+$ ) level of confidence. Most of the shielding properties of concrete or ducrete are reasonably well-known. Less confident in thermal properties, such as heat dissipation off of the waste packages.

Construction, Operations and Maintenance-

Moderate $(\mathrm{C}+)$ level of confidence. The processes are fairly straightforward.

\section{Schedule-}

Moderately low $(\mathrm{D}+)$ level of confidence. The schedule impacts of possible additional site characterization and licensing are significant unknowns.

Cost-

Moderate (C) level of confidence. Do not have all of the information yet.

\section{DF 14 - WP CRMs (Metal and Ceramic)}


QAP 3-12

Request for Design Input

$2 / 1 / 99$

Postclosure Performance (LDE) -

Moderately high (B) level of confidence. Some failure mechanisms are not addressed (e.g., stress corrosion cracking). Long-term phase stability and passive film stability are also not addressed.

Postclosure Performance (PA Analyst) -

Metal and ceramic option: Low (E) level of confidence. Virtually no plausible

degradation mode data are available for ceramic coatings. Degradation modes for metals have not been fully addressed.

Titanium option: Moderately low (D) level of confidence. The patch failure time profile is based on a large data set, however, most of the data were obtained from tests run for less than one year. Data collected over a longer time period are needed. Mechanical corrosion (including SCC and hydride cracking) is not considered in the model, which is a major model weakness.

Preclosure Performance-

High (A) level of confidence. No impacts are expected.

Assurance of Safety-

Moderately high (B) level of confidence. The passive film degradation issue will be difficult to resolve.

Engineering Acceptance-

High (A) level of confidence. (basis?)

Construction, Operations, and Maintenance-

High (A) level of confidence. (basis?)

\section{Schedule-}

Moderately high (B) level of confidence. This feature is similar to the VA base case plan.

Cost-

Moderately high (B) level of confidence. Good cost estimates, including for fabrication, have been made.

\section{DF 15 - RICHARDS BARRIER}

Postclosure Performance (LDE) -

Moderately low (D) level of confidence. There is uncertainty in the effective lifetime of the barrier, thus pre-selected failure times (e.g., $2 \mathrm{~K}, 8 \mathrm{~K}$, etc. -check) are used in PA models. These times are essentially just assumptions without much basis. 
QAP 3-12

Request for Design Input

$2 / 1 / 99$

Postclosure Performance (PA Analyst) -

Low (E) level of confidence. No model is available for the lifetime of the barrier, however a sensitivity case has been run. It is not known how effective seepage diversion would be and how long diversion would last.

Preclosure Performance-

NA

Assurance of Safety-

Moderate (C) level of confidence. Tests and studies currently planned and underway will provide information valuable for defining uncertainties.

Engineering Acceptance-

Moderately high (B) level of confidence. There are engineered analogs that, while not quite analogous, provide useful data. Laboratory data are also available, although the scale-up will be difficult. The lifetime of the system is also uncertain.

Construction, Operations, and Maintenance-

Moderately high (B) level of confidence. This feature can be designed to be safe. It is likely that prototypes and additional testing will be needed.

\section{Schedule-}

Moderate $(\mathrm{C})$ level of confidence. There are uncertainties in the machinery to be used and construction efficiency.

Cost-

Moderate (C) level of confidence. There are uncertainties in design and construction.

\section{DF 16 and 17 -- DIFFUSIVE BARRIER UNDER THE WASTE PACKAGE AND GETTER (treated together)}

Postclosure Performance (LDE) -

Diffusive barrier -- Moderate (C) level of confidence. Performance will be tied to inflow of water so the level of uncertainty is high. The materials to be used are well characterized in the laboratory.

Getter-- Moderately low (D) level of confidence. Geochemistry is highly uncertain.

\section{Postclosure Performance (PA Analyst) -}

Moderately low (D) level of confidence. There are many questions regarding the design and potential performance of this feature: how thick should the barrier be, will it become saturated or be washed away by the time radionuclides are released, will the material used improve the environment for microbes and increase MIC? 
QAP 3-12

Request for Design Input

2/1/99

Preclosure Performance--

High (A) level of confidence. No effect on DBEs.

Assurance of Safety--

Diffusive barrier -- Moderate (C) level of confidence. (Same basis as in Postclosure performance)

Getter-- Moderately low (D) level of confidence. (Same basis as in Postclosure performance)

\section{Engineering Acceptance-}

Moderate (C) level of confidence. Engineering protocols will be followed in design and construction plans.

Construction, Operations, and Maintenance-

High (A) level of confidence. Since this feature can be constructed before WP emplaced there is high confidence in effective construction. No operations or maintenance will occur.

\section{Schedule -}

Moderately high (B) level of confidence. Emplacement of this feature would have to be meshed with other construction activities.

\section{Cost-}

Moderately high (B) level of confidence. Materials cost and construction straightforward.

\section{DF 18 - CANISTERED ASSEMBLIES}

\section{Postclosure Performance (LDE) -}

Moderate $(\mathrm{C})$ level of confidence. Corrosion models require more study and testing.

Postclosure Performance (PA Analyst) -

Moderately high (B) level of confidence. Adding an additional layer of CRM (from the canistered assemblies) results in a smaller performance range.

\section{Preclosure Performance-}

Moderate (C) level of confidence. Additional lifts involved, but they occur with canistered assemblies so should be limited consequences.

\section{Assurance of Safety-}

Moderately high (B) level of confidence. Additional packages should mitigate uncertainties in performance. 
QAP 3-12

Request for Design Input

$2 / 1 / 99$

Engineering Acceptance-

Moderately high (B) level of confidence. The thin canister walls could complicate construction.

Construction, Operations and Maintenance-

Low (E) level of confidence. Presently have incomplete input.

Schedule-

High (A) level of confidence. Straightforward to estimate.

Cost-

Do not have this information.

\section{DF 19 - ADDITIVES AND FILLERS}

Postclosure Performance (LDE) -

Moderately low (D+) level of confidence. There are few data, many modeling assumptions, and lack of benchmarking.

Postclosure Performance (PA Analyst) -

Moderate (C) level of confidence for basket and oxide powder options and moderately high (B) level of confidence for iron shot option. With the basket and oxide powder options, an infinite sorption capacity is assumed, which is not realistic. With the iron shot option the cladding is assumed to be gone, which eliminates the uncertainty associated with cladding.

Preclosure Performance-

Moderately high $(\mathrm{B}+)$ level of confidence. The operations are straightforward and routine.

Assurance of Safety-

High (A) level of confidence. (basis??)

Engineering Acceptance-

High (A) level of confidence. This is a simple mechanical operation.

Construction, Operations and Maintenance-

High (A) level of confidence. (basis??)

\section{Schedule-}

High (A) level of confidence. (basis??)

Cost-

High (A) level of confidence. (basis??) 
QAP 3-12

Request for Design Input

$2 / 1 / 99$

\section{DF 20 - GROUND SUPPORT OPTIONS}

There are 3 ground support options considered: unlined (rock bolts), steel lined, and concrete lined. The VA reference design calls for $90 \%$ of the drift to be lined with prepored concrete, and $10 \%$ to be steel-lined; if concrete is found to be not suitable, all drifts can be lined with steel sets.

\section{Postclosure Performance (LDE) -}

Moderately low (D) level of confidence. PA models do not address this issue in detail. The models are the same for both steel sets and concrete, thus the many variables associated with concrete, and the amount of concrete used, are not modeled. Models also are not available for rock fall, which could be affected by the type of ground support.

\section{Postclosure Performance (PA Analyst) -}

20A - Steel set option: moderately high (B) level of confidence. A metal lined drift does not play a role in performance. Uncertainty related to performance of concrete is removed with this option.

$20 \mathrm{~B}$ and 20C-Concrete options: moderately low (D) level of confidence. The possible effects of concrete on the waste packages are not understood and are not accounted for the PA model.

\section{Preclosure Performance-}

High (A) level of confidence for steel sets and concrete; moderate (3) level of confidence for rock bolts. Rock fall is the DBE. Data are not available on the use of rock bolts for time periods longer than about 25 years. It is unclear if rock bolts could be designed to adequately hold key rock blocks susceptible to failure. Ground support will have to be designed based on preclosure access to drifts (i.e., if people will enter drifts, a more secure system will be necessary.)

\section{Assurance of Safety-}

Moderately high (B) level of confidence for steel sets; moderate (C) level of confidence for rock bolts; moderately low (D) level of confidence for concrete. Steel set systems are well understood. Concrete appears to be a good material for the anticipated temperatures, stress levels, and long time periods anticipated in emplacement drifts. However, there is uncertainty in the postclosure behavior of concrete, and this will be difficult to reduce.

\section{Engineering Acceptance-}

Moderate $(\mathrm{C}+$ ) level of confidence. Designs for steel sets and concrete may require modifications to allow stress release. There are few precedents for such stress release elements, and demonstrating them will not be simple.

\section{Construction, Operation and Maintenance-}

Moderately high (B) level of confidence. Steel sets would be needed to minimize maintenance; bolts and wire mesh could have maintenance issues within a 100 year period. 


\section{QAP 3-12}

Request for Design Input

$2 / 1 / 99$

\section{Schedule-}

High (A) level of confidence. Similar to the VA design. The two- pass system needed for steel sets would require more installation time than rock bolts.

\section{Cost-}

High (A) level of confidence. Currently 12 different ground support system types have been analyzed and it is relatively easy to calculate cost on a per unit basis.

\section{DF 22 -- NF ROCK TREATMENT DURING CONSTRUCTION}

\section{Postclosure Performance (LDE) -}

Moderately low (D) level of confidence. Modeling indicates the change in seepage rate with this DF is very small $(<10 \%)$ so there will be a negligible impact on peak dose rate. The reasons for this small change are not well understood.

Postclosure Performance (PA Analyst) -

Moderate (C) level of confidence. Modeling uncertainty is related to problems with initial fracture porosity (which scales the effect) and coupling laws (i.e., if hydraulic properties are changed, assumptions have to be made on how the change affects other properties.)

\section{Preclosure Performance-}

Moderately high (B) level of confidence. Once rock temperatures are above boiling, little effect on Preclosure performance is anticipated.

\section{Assurance of Safety-}

Moderately high (B) level of confidence. Limited testing and analysis have been conducted so behavior is uncertain. However, there is high confidence that additional data can be obtained prior to closure.

\section{Engineering Acceptance-}

Moderately high (B) level of confidence. Limited data are available: materials anticipated for use (calcite) do not have strong precedent and the time frame is untested (i.e., no data are available for time frames on the order of 1,000 s of years.)

\section{Construction, Operations and Maintenance-}

Moderately high (B) level of confidence. The proposed system is relatively simple to install.

\section{Schedule-}

Moderately low (D) level of confidence. Limited data are available on rock properties throughout the repository. Construction progress rates are uncertain as ground modification typically is used to fill fault voids. 


\section{QAP 3-12}

Request for Design Input

$2 / 1 / 99$

Cost--

Moderately low (D) level of confidence. Preliminary cost estimates are based on limited information regarding materials and rock conditions over the total repository area. The uncertainties in the schedule will have a strong effect on cost.

\section{DF 23 - SURFACE MODIFICATIONS}

Two implementations of this feature are considered: 23a) grading the mountain and placing a $2.5 \mathrm{~m}$ thick blanket of alluvium over the region; and 23b) removing alluvium from the slopes and gulleys.

\section{3a-Alluvium Added}

Postclosure Performance (LDE) -

Moderate (C) level of confidence. Possible failure scenarios have not been evaluated (eg. drought or fire that destroys the vegetation). The PA model doesn't allow for leaving the existing alluvium and adding only to the cut areas. The principal model comes from the net infiltration maps and preferential pathways-and their effect on drips into the driftsare not considered.

\section{Postclosure Performance (PA Analyst) -}

Moderate $(\mathrm{C})$ level of confidence. PA calculations indicate percolation flux is reduced by about 2 orders of magnitude and there would be no seepage into the drift. However, the lifetime of the feature is highly uncertain; PA analysts arbitrarily selected 5,000 year and 10,000 year lifetimes for their calculations.

\section{Preclosure Performance-}

High (A) level of confidence. No increase in DBEs expected.

\section{Assurance of Safety-}

Moderate (C) level of confidence. There is some uncertainty in how the system will work. Details of net infiltration (e.g., preferential pathways) need additional study.

\section{Engineering Acceptance-}

Moderately high (B) level of confidence. Concept is straightforward and easy to understand.

\section{Construction, Operations and Maintenance-}

High (A) level of confidence. Safety issues are well understood and there are no radioactive hazards.

\section{Schedule-}

(Need response)

\section{Cost--}

Moderate (B) level of confidence. (basis?) 
QAP 3-12

Request for Design Input

$2 / 1 / 99$

\section{3b--Alluvium Removed}

Postclosure Performance (LDE) -

Moderate (C) level of confidence. A net infiltration simulation was run with all alluvium removed, however, this is not realistic.

\section{Postclosure Performance (PA Analyst)}

Moderately high (B) level of confidence. The net infiltration models developed by USGS are well accepted. Calculations have shown that the infiltration rate with this feature will be much higher than at present.

Preclosure Performance-

High (A) level of confidence. Limited effect on the preclosure period.

\section{Assurance of Safety-}

High (A) level of confidence. The net infiltration simulation indicated storage capacity of the rock was exceeded, and downstream conditions were overloaded.

\section{Engineering Acceptance-}

Moderately low (D) level of confidence. Earth moving operations will be difficult, particularly cutting without filling.

Construction, Operations and Maintenance-

High (A) level of confidence. This is straightforward; the industrial safety aspect is wellunderstood.

\section{Schedule-}

(Need Response)

Cost-

(Need response)

\section{DF 25 --HORIZON ELEVATION}

Relocated option: repository moved up $50 \mathrm{~m}$ vertically.

Two-tier option: build repository in 2 tiers, one above the other, so same drift and WP spacing.

\section{Postclosure Performance (LDE) -}

Relocated option: moderately high (B) level of confidence. No effect on performance. Two-tier option: moderately low (D) level of confidence. PA modeling will be imprecise because the two-tier system has not been modeled; the performance is interpolated from the VA base case model.

Postclosure Performance (PA Analyst) -

No change in performance 
QAP 3-12

Request for Design Input

$2 / 1 / 99$

Preclosure Performance-

Moderately high (B) level of confidence. Similar to VA base case plan.

Assurance of Safety-

Relocated option: high (B) level of confidence. Similar to VA base case plan.

Two-tier option: moderate (C) level of confidence. This design will be difficult to assess.

\section{Engineering Acceptance-}

Moderate (C) level of confidence. Some aspects of the feature are uncertain, but no major problems are anticipated

\section{Construction, Operation and Maintenance-}

Moderately high (B) level of confidence. The two-tier option will require a new PC design.

\section{Schedule}

Relocated option: high (B) level of confidence. Similar to VA base case plan.

Two-tier option: moderate (C) level of confidence. A construction schedule has not been developed. If a specific schedule had to be met, more equipment could be used, however electrical power consumption and other factors could be affected.

Cost

Moderately high (B) level of confidence. (both options?)

\section{DF 26 --HIGHER THERMAL LOAD}

Postclosure Performance (LDE) -

NR (not familiar with PA models)

Postclosure Performance (PA Analyst) -

Moderate (C) level of confidence. Confidence is higher on thermal issues and lower on relative humidity issues. The RH values are more uncertain because of possible irreversible changes in rock properties following the thermal period. The local distribution of the seepage flux is not well represented.

\section{Preclosure Performance-}

NA

Assurance of Safety-

Moderate (C) level of confidence. Relies on difficult-to-demonstrate, novel modeling approaches. 
QAP 3-12

Request for Design Input

2/1/99

Engineering Acceptance-

Moderate (C) level of confidence. Consistent with accepted principles. Geysers are a natural analog (i.e., as water is heated the pressure rises and the water is driven out of the ground); another possible analog is the behavior of a Mt. St. Helens ice field during the volcanic eruption.

Construction, Operations and Maintenance-

Moderately high (B) level of confidence. (basis?)

\section{Schedule-}

Moderate (C) level of confidence. Innovative concept that could require more time to support during LA.

\section{Cost-}

Moderate (C) level of confidence. Construction would be similar to that planned for the VA base case, although additional subsurface work would be required. 
QAP 3-12

Request for Design Input

$2 / 1 / 99$

DESIGN ALTERNATIVES

\section{DA 1 - TAILORED WASTE PACKAGE SPATIAL DISTRIBUTION}

\section{Postclosure Performance (LDE)-}

Moderately high (B) level of confidence. Subjective view of postclosure performance based on notional characterization of grouping waste packages according to percolation flux and segregated according to heat output. No correlations found between these aspects and performance.

\section{Postclosure Performance (PA Analyst)-}

NA (no calculations conducted)

Preclosure Performance-

Moderate $(\mathrm{C}+)$ level of confidence. Assuming the same waste stream coming to the repository, some uncertainties in areas needed for storing and staging.

Assurance of Safety -

Moderate $(\mathrm{C}+)$ level of confidence. Uncertainties in performance are significant.

Engineering Acceptance-

Moderately high (B) level of confidence. There is nothing new relative to the VA reference design.

Construction, Operations and Maintenance-

Moderate $(\mathrm{C}+)$ level of confidence. Elements are fairly well-known.

\section{Schedule-}

Low (E) level of confidence. It is known that this will take more time than the reference design, but until a better design can be determined (e.g., distribute waste packages according to percolation flux), uncertainties are very high.

\section{Cost-}

Moderately low (D) level of confidence. Estimates of unit costs are high confidence, but until the number of motions is established, the total cost is highly uncertain.

\section{DA 2 - LOW THERMAL LOAD DESIGN}

Postclosure Performance (LDE) -

Moderate to moderately high $(\mathrm{C}+)$ level of confidence. Confidence in this alternative is fairly high because coupled effects do not need to be modeled, thus eliminating this source of uncertainty. There is uncertainty in corrosion rates of the waste packages. Corrosion rate distributions were obtained from the WPDEE project, however, the distributions are very broad. There are also uncertainties in rock parameters, but this is a secondary issue.

$$
\text { of } 210826
$$


QAP 3-12

Request for Design Input

$2 / 1 / 99$

\section{Postclosure Performance (PA Analyst)-}

Low (E) level of confidence. A PA model that compares low thermal conditions to high thermal conditions is not available. Current models use temperature and relative humidity as discriminators, with no implications to flux (i.e., seepage is non-isothermal). However, since low thermal conditions result in less dry out, more water is available to flow into drift and this has important implications for waste packages.

\section{Preclosure Performance-}

Moderate (C) level of confidence. Engineering judgment will be used to minimize DBEs.

\section{Assurance of Safety -}

High (A) level of confidence. This alternative minimizes uncertainties related to nearfield coupled processes.

\section{Engineering Acceptance-}

Moderately high $(\mathrm{B}+$ ) level of confidence. The engineering concept is clear. Additional data will be available for licensing.

\section{Construction, Operations and Maintenance--}

Moderately high (B) level of confidence. No new or different equipment will be required. More construction activity will be necessary, so worker safety is potentially increased.

\section{Schedule-}

Moderate (C) level of confidence. It may be necessary to go into the licensing stage with a low thermal plan for the core area, then characterize the additional repository footprint with extra borings and other studies. The current planned schedule should not change significantly.

Cost-

Moderately low (D) level of confidence. Additional detail cost analysis is needed.

\section{DA 3 - CONTINUOUS POSTCLOSURE VENTILATION DESIGN}

Three options are considered: a closed-loop concept, an open-loop concept and a closed/open-loop concept. The latter option is not as well developed as the former two.

\section{Postclosure Performance (LDE) -}

Moderate (C) level of confidence. PA models are straightforward. Rockfall has not been completely modeled and incorporated.

\section{Postclosure Performance (PA Analyst)-}

Low (E) level of confidence. Additional work is needed to integrate ventilation issues into PA. Preliminary results are similar to VA base case results. Failure modes are not incorporated. Thermodynamic equilibrium assumptions may not be correct. 
QAP 3-12

Request for Design Input

$2 / 1 / 99$

Preclosure Performance-

High (A) level of confidence. This alternative may not effect pre-closure performance.

Assurance of Safety-

Moderate (C) level of confidence. Long-term survivability of open drifts and shafts is uncertain. Obstruction from rock falls could negate the system; this possible scenario will be difficult to defend in the licensing stage. The potential for air-borne releases is uncertain.

Engineering Acceptance -

Closed-loop option: moderately high $(\mathrm{C}+)$ level of confidence. The amount of moisture that will be re-circulated is uncertain.

Open-loop option: high (A) level of confidence. This alternative is similar to the VA base case.

Closed/open-loop option: moderate (C) level of confidence. This alternative would require additional study.

It has not been clearly demonstrated that moisture removal is effective protection for the waste packages. There is moderate confidence that the ventilation system will operate for more than 10,000 yrs., but rockfall effects are a fundamental question.

Construction, Operations, and Maintenance -

Moderately high (B) level of confidence. The construction of a larger number of drifts will result in greater risk to workers.

\section{Schedule-}

Moderate (C) level of confidence. The open-loop option could require additional time for licensing questions. The closed/open-loop would require additional construction (separate shafts, ramps, and access points) beyond what is planned for the VA base case.

\section{Cost-}

Moderately high (B) level of confidence for closed-loop and open-loop options. A design has not been developed for the closed/open-loop option, so no cost estimates are available. Further analysis of the closed/open-loop option could be very useful; drift cost would probably about $2 \mathrm{x}$ the VA base case design.

\section{DF 4 - ENHANCED ACCESS DESIGN}

Three implementation options are considered: integral shield option and supplemental shield options for the waste package, and a shielded cart option to allow personnel access.

Postclosure Performance (LDE)-

Moderate $(C)$ level of confidence. Limited knowledge of the PA models.

Postclosure Performance (PA Analyst)-

NA 
QAP 3-12

Request for Design Input

$2 / 1 / 99$

\section{Preclosure Performance-}

Moderately high (B) level of confidence. There will be a net benefit on overall

performance. There will be additional protection from rock fall.

\section{Assurance of Safety -}

Integral shield and shielded cart options: moderately high $(B)$ level of confidence. There is a decrease in the uncertainty of meeting overall repository objectives.

Supplemental shield option: moderately low (D) level of confidence. Concrete shielding would provide some performance benefits, but radionuclide retention is uncertain.

\section{Engineering Assessment-}

Integral shield option: moderately high (B) level of confidence. There are licensing precedents for this option. (also supplemental shield?)

Shielded cart option : moderately low (D) level of confidence. This option would require a sophisticated design and construction process.

\section{Construction, Operations and Maintenance -}

Integral shield and supplemental shield options: moderately high (B) level of confidence. Access for personnel are traded off with the potential for additional radiation dose.

Shielded cart option: moderate (C) level of confidence. The equipment is fixed, which takes away flexibility for maintainability.

\section{Schedule -}

Moderately high (B) level of confidence.

\section{Cost -}

Integral shield option: moderately low (D) level of confidence.

Supplemental shield option: moderately high (B) level of confidence.

Shielded cart option: low (E) level of confidence. Additional information is needed.

\section{DA 5 - MODIFIED WASTE EMPLACEMENT MODE DESIGN}

\section{Postclosure Performance (LDE)-}

Moderately high (B) level of confidence for the short cross-drifts implementation; Moderate (C) level of confidence for vertical boreholes; and Moderately low (2) for the concrete or marble trench design. Little data or modeling has been done to evaluate the postclosure performance of the trench designs.

\section{Postclosure Performance (PA Analyst)-}

Marble lining option: moderate (C) level of confidence. There are material uncertainties: e.g., marble could crack during thermal pulse, annealing could occur. The source of the marble and the criteria for its selection (i.e., material that is stressed would not be stable), would have to be assessed. 
QAP 3-12

Request for Design Input

$2 / 1 / 99$

Preclosure Performance-

Moderate (C) level of confidence. More thinking about pre-closure implications is needed.

Assurance of Safety -

Moderate (C) level of confidence. There are uncertainties in postclosure performance but there are potentially useful data (e.g., chemical analyses of marble-affected water).

\section{Engineering Acceptance-}

Moderate (C) level of confidence. (Need input from designers)

Construction, Operations and Maintenance-

Moderately high (B) level of confidence. Operations are fairly well-constrained.

Performance confirmation may have lower confidence.

Schedule-

Moderately low (D) level of confidence. Uncertainties in the constructability may be an issue. The schedule seems aggressive.

Cost-

Low (E) level of confidence. Need additional information.

\section{DA 6 - VA REFERENCE DESIGN}

\section{Postclosure Performance (LDE)-}

Postclosure Performance (PA Analyst)-

Moderate $(C)$ level of confidence. Seepage is the most important performance parameter (up to $50 \%$ of out put), and a wide range of values have been considered. Concrete is also important; it has been assumed that seepage does not touch concrete before reaching waste packages. The SZ modeling and dilution factors should be improved.

\section{Preclosure Performance-}

\section{Assurance of Safety -}

Moderately high (B) level of confidence. There does not appear to be much defense-indepth. Many uncertainties have been considered.

\section{Engineering Acceptance-}

Moderately low (D) level of confidence. There are significant model uncertainties and the availability of data is limited. 
QAP 3-12

Request for Design Input

2/1/99

Construction, Operations and Maintenance-

Moderate (C) level of confidence. Uncertainties in remote operations and repair. Schedule-

Moderately high (B) to moderately low ( $\mathrm{D}+$ ) level of confidence, according to the repository stage considered. The schedule assigned for the design stage has moderately low confidence and for the emplacement stage has moderately high confidence.

Cost-

High (A) level of confidence. Considerable amount of study has been done. 